\title{
The Application of CBL Teaching Combined with PBL Teaching Method in Biochemistry Experiment Teaching
}

\author{
Junhong Dong ${ }^{1, a *}$ and Ping Zeng ${ }^{2, b}$ \\ 1,2Weifang Medical College,Weifang 261042, China \\ adjh196@163.com, ${ }^{b}$ zengp1994@126.com \\ *The corresponding author
}

Keywords: PBL; CBL; Biochemistry; Biochemistry experiment teaching

\begin{abstract}
To investigate the effect of case teaching combined with PBL teaching method in biochemistry experiment teaching. Methods: The four classes of clinical 2015 undergraduate students were randomly divided into two groups, the experimental group used CBL teaching combined with PB teaching mode, the control group using traditional teaching method teaching. Through the questionnaire survey and test scores in two ways to evaluate the teaching effect. Results: The experimental group is superior to the control group, and it is statistically significant ( $\mathrm{P}$ $<0.05$ ) in the experimental group, and in the aspects of improving the learning interest, classroom participation consciousness and language expression. Conclusions: Compared with the traditional teaching method, the new teaching method can improve the students' comprehensive ability, can be basic knowledge and professional knowledge in close contact for students to enter the clinical stage of learning to lay a good foundation.
\end{abstract}

\section{Introduction}

In the medical education curriculum, the medical basic courses and clinical courses are independent of each other, lack of extensive and in-depth contact. Biochemistry and molecular biology as a medical discipline of a basic discipline, because of its theoretical abstraction, difficult to understand, many students' learning enthusiasm of the course is not high, the teaching effect is not ideal $[1,2]$. CBL teaching method (case -based learning ) is case teaching method, first proposed by the United States Harvard University C.C.Langdell. The teaching method to teaching syllabus as a guide, design a typical case for teaching content, Students review the information reflected in the case by reviewing, reviewing the textbook knowledge and consulting the relevant information. To further deepen the understanding and mastery of concepts and theories [3]. PBL teaching method (problem-based learning) is the problem of teaching method, this education model is proposed by the 1960s American educator Barrow stichu [4]. The teaching method is that the teacher according to the teaching requirements to ask questions and guide students to discuss a group of is sues around the study, stimulate students' interest in learning, train students' ability to think and solve problems independently. The above two kinds of teaching models are based on student self-learning, changed the teaching model based on teacher teaching, aimed at cultivating students to explore the spirit of innovation, which CBL teaching method emphasizes the application of comprehensive knowledge, the PBL teaching method is more focused on the ability to solve specific and detailed problems. Experimental teaching is an important part of higher education in our country, is an important way to cultivate college students' innovative spirit and innovation ability [5-7]. This topic will be two kinds of teaching methods combined with each other, learn from each other, applied to biochemistry experiment teaching and evaluating teaching effect. Students are seeking and exploring problem-solving activities, In the activities of seek and explore problem solving, Students master the knowledge, develop skills, improve the comprehensive ability, laid a solid theoretical foundation for the clinical stage of learning. 


\section{Organization of the Text}

Subjects. Select the 2015 undergraduate students of clinical medicine for the study, the total number is 179.The clinical 1,4 classes were used as experimental groups, a total of 90 people, the clinical 2,5 classes were used as control group, a total of 89 people. Experimental class to take PBL joint case teaching method, the control class is taught according to the traditional teaching mode.

Course Design: Biochemistry experiment course is currently open 10 experimental operations, of which 6 is the basic theory, the basic operation and validation experiments, the remaining four are comprehensive and design experiments. On the experimental group of classes, carefully selected four comprehensive and design experimental courses using PBL joint case-based teaching model, the case covers many chapters of biochemistry and the corresponding laboratory techniques; The control group of the whole class using traditional teaching method. The problem has been completed was arranged 2 weeks before class in experimental class. The problem is based on the syllabus, often with "uncertainty"; Grouping for retrieval before class, access to relevant information, class discussion in class, the reporter must be rotated, the instructor is responsible for guiding, analyzing and concluding the final summary. The control class is taught by the teacher.

Evaluation method: After the end of the course, using the experimental assessment and questionnaires in two ways to evaluate the teaching effect. The experimental examination was divided into three parts: classroom performance (40\%), experimental operation (40\%) and experimental report (20\%), experimental operation is a single assessment, requiring students to complete a specific experimental operation independently, focusing on students' practical ability. There were eight questions in the questionnaire, and the PBL combined case study group and the control group were surveyed by secret method. Each question was positive or negative. Data were analyzed by SPSS15.0 statistical software. Data were expressed as mean \pm standard deviation. Comparison between groups using $\mathrm{t}$ test, $\mathrm{P}<0.05$ was statistically significant.

\section{Results}

Test scores. Comparing the experimental results of PBL combined with LBL teaching group and control teaching group, The results showed that the differences between the two groups in classroom

performance, experimental report and total score were statistically significant $(\mathrm{P}<0.05)$. There was no significant difference between the two groups $(\mathrm{P}>0.05)$. Examination results are shown in Table1.

Table 1 Comparison of Test Results between PBL and LBL Teaching Group and Control Teaching Group $\left(\mathrm{X}_{ \pm} \mathrm{SD}\right)$

\begin{tabular}{lcccc}
\hline \multicolumn{1}{c}{ Project } & Classroom performance & Experiment operation & Report & Total score \\
\hline PBL + LBL group & $35.71 \pm 4.24$ & $34.64 \pm 5.09$ & $16.11 \pm 3.48$ & $83.27 \pm 4.18$ \\
Control group & $33.58 \pm 4.17 \star$ & $32.66 \pm 4.71$ & $13.83 \pm 4.11 \star$ & $79.27 \pm 5.25 \star$ \\
Statistics & $\mathrm{t}=2.931$ & $\mathrm{t}=1.0997$ & $\mathrm{t}=4.457$ & $\mathrm{t}=6.258$ \\
\hline
\end{tabular}

$* \mathrm{P}<0.05$ was statistically significant

Questionnaire survey. The questionnaire was filled by two groups of students, a total of 179 questionnaires were distributed and 179 were recovered with a recovery rate of $100 \%$.PBL combined with the LBL group survey showed that about $96.7 \%$ of the students affirmed the effect of the joint teaching method in the study of interest, classroom participation, language skills, teamwork and classroom knowledge and other aspects of the ability. 51.6\% of the students are willing to use only traditional teaching in the future teaching mode, $95.6 \%$ of students are willing to implement PBL in the future teaching model combined with LBL teaching model. Compared with 
the control group, all aspects were statistically significant, see Table 2.

Table 2 Comparison of teaching effect between PBL combined with CBL group and control group

\begin{tabular}{lcc}
\hline \multicolumn{1}{c}{ Project } & \multicolumn{2}{c}{ Finding results[n(\%)] } \\
& PBL+CBL & Control \\
\hline Improve learning interest & $87(96.7)$ & $48(65.1)^{*}$ \\
Improve classroom participation & $88(97.8)$ & $26(29.2)^{* *}$ \\
Improve self-learning ability & $82(91.1)$ & $51(57.3)^{* *}$ \\
Improve language skills & $79(87.8)$ & $45(50.1)^{*}$ \\
Improve teamwork & $75(83.3)$ & $50(56.1)^{*}$ \\
Improve the ability to master classroom knowledge & $81(90.0)$ & $62(69.7)^{*}$ \\
Improve clinical thinking ability & $88(97.8)$ & $58(65.2)^{*}$ \\
Whether it is applied in follow-up courses & $86(95.6)$ & $46(51.6)^{* *}$ \\
\hline
\end{tabular}

$* \mathrm{P}<0.05,{ }^{* *} \mathrm{P}<0.01$ were statistically significant

\section{Discussion}

This study analyzes the effect of different teaching methods on the teaching effect as independent variables. The experimental group used CBL combined with PBL teaching method, the control group using the traditional teaching method. The survey results show that CBL combined with PBL teaching method in student learning initiative, cultivate self-learning ability, analysis of problem-solving ability, language ability and so on are significantly improved. CBL combined with PBL teaching method is better than traditional teaching method in student feedback. $91.1 \%$ of the students in the experimental group believe that the new teaching method can cultivate self-learning ability and innovation ability; more than $90 \%$ of the students think that can improve the ability to analyze, solve problems, language skills and team awareness. By comparing the results of two groups of students, found that the experimental group of students was significantly higher than the total score of the control group. In summary, CBL combined with PBL teaching method in the biochemistry experiment class teaching effect is superior to the traditional teaching method. CB combined with PBL teaching method achieved the change from teachers teach questions to guide students to solve problems. The implementation of the new teaching method not only more clear the purpose of experimental teaching, increase students' attention to biochemistry, so that they are willing to take the initiative to think, but also to penetrate each subject knowledge, broaden the knowledge, ahead of the clinical knowledge into the classroom, training students clinical thinking, lay a better foundation for its future study. The implementation of the new teaching method, enable students to learn to use reference books, network and library resources and other channels to learn. Using the way of classroom discussion, increase the interaction between students and teachers in the classroom, active classroom atmosphere, increase students' interest in learning, is conducive to cultivating innovative professional talents. It should be noted that the choice of case is the key to success or failure of CBL combined with PBL teaching, good case can not only stimulate students' interest in learning, but also reflect the teaching objectives and requirements. This requires teachers not only to have a solid theoretical basis of knowledge, but also a wealth of clinical knowledge [8] . Due to limited hours, teachers should be fully prepared before the work, on the possible problems in the classroom should be predictable, grasp the rhythm of teaching, timely guide students to explore knowledge, control the direction and content depth, adjust the classroom atmosphere, to ensure the smooth progress of teaching to achieve the desired teaching results. Teachers should sum up, complement and optimize the teaching content of each lesson, evaluate students' response and learning ability in class. The new teaching method requires teachers to change their teaching ideas, 
from the traditional teaching knowledge to advocate students to explore knowledge with inspiration and discussion $[9,10]$. The differences of students' knowledge structure and knowledge background should be considered, as far as possible to each group can have different levels of students, increase students exchange and learning opportunities, to increase the opportunities for students to communicate and learn. Not only to provide a learning opportunity for students with poor self-learning ability, but also is the influencing factors of the teaching effect of the new teaching method.

\section{Acknowledgements}

This work was supported by Key Project of Educational Reform and Research in Weifang Medical College(2016Z0201).

\section{References}

[1] Z.W.Zhang, Ch.Y.Hao, Yan Bo, Constructing New Teaching Model of Biochemistry Experiment to Promote Innovative Medical personnel training, Laboratory Science. 8 (2015) 114-116..

[2] F.Fan: Case, Study of PBL Teaching Method in Biochemistry Teaching, Basic Medical Education. 16 (2014) 95-96.

[3] L.B. Barnes, C .R. Christen, A.J.Hansen, Teaching with cases at the Harvard Business School,Boston, 1994.Refence to a chapter in an edited book.

[4] MCPARLAND M, NOBLE L M, LIVINGSTON G, The effectiveness of Problem based learning compared to tradition teaching in undergraduate Psychiatry,Medical Education.38 (2004) 85.-86 .

[5] Zhang Zh. W.Zhang, H.L.Wei, Ch.Y.Hao, PBL combined with LBL teaching method inbiochemistry experimental teaching application, laboratory science.28 (2017) 113-116.

[6] Graham D Hendry, Patricai M.Lyon, Conceptions of problem-based learning: the perspectives of students entering a problem-based medical program, Medical Teacher. 28 (2015) 573-575..

[7] X.X.Guo, Ch.H.Li, L.Zhang, PBL combined with case-based teaching method in the application of biochemistry teaching practice, Anhui Agricultural Sciences.40 (2012) 15546-15547.

[8] Catherine J Rowan, Christine Mc Court, Debra, Bick, Problem-based learning in midwifery-The teachers perspective, Nurse Education Today.11 (2007) 131-138.

[9] Li Hua, Wang Li, Lin Yuan, On the application of case - based teaching method in medical basic education, Journal of Science and Education Innovation. 1 (2012) 85.

[10] H.W.Wu, Zhao R. Cheng, Sh.l.Gao, The application of LBL and PBL teaching model in physiology teaching and its effect evaluation, Advances in Modern Biomedicine.15 (2015) 1339-1341. . 